\title{
Vinhaça como fonte de potássio: resposta da sucessão aveia-preta/milho silagem/milho safrinha e alterações químicas do solo na Região Noroeste do Rio Grande do Sul
}

\author{
Vinasse as a source of potassium: black oat/corn silage/short-season corn succession response \\ and soil chemical alterations in the Northwest region of the state of Rio Grande do Sul
}

\author{
Claudir José Basso ${ }^{\mathrm{I}}$ Antônio Luis Santi ${ }^{\mathrm{I}}$ Fabiane Pinto Lamego ${ }^{\mathrm{I}}$ Lucindo Somavilla ${ }^{\mathrm{II}}$ \\ Tiago José Brigo
}

\section{RESUMO}

A vinhaça, resíduo do processo de destilação do álcool é rica em potássio $(K)$ e sua aplicação ao solo pode aumentar a disponibilidade do nutriente, mas também provocar alterações nas propriedades químicas do solo. O trabalho objetivou avaliar a viabilidade técnica da utilização da vinhaça como fonte alternativa de $K$ na sucessão aveia preta/milho silagem/milho safrinha, além de possíveis alterações em atributos químicos do solo na camada de $0-10 \mathrm{~cm}$. O experimento foi conduzido no Município de Ajuricaba (RS), no período 04/2010 a 06/2011. Os tratamentos utilizados foram: T1) adubação mineral $N P K$; T2) N + P sem vinhaça; T3) $N+P+50 m^{3} h a^{-1}$ de vinhaça; T4) $N+P+100 m^{3} h a^{-1}$ de vinhaça; T5) $N+P+150 m^{3} h^{-1}$ de vinhaça; $e$ T6) $N+P+200 m^{3} h^{-1}$ de vinhaça. Na aveia preta, foram avaliados os teores totais foliares de $P, K$ e o acúmulo de matéria seca. No milho silagem, a altura de plantas, altura de inserção da espiga e a produtividade de forragem e, no milho safrinha, o peso de mil sementes e a produtividade de grãos. Quanto aos atributos químicos do solo, foi avaliado o $\mathrm{pH}$, os teores de $\mathrm{P}, \mathrm{K}, \mathrm{Ca}, \mathrm{Mg}$ e a capacidade de troca cationica. Na aveia-preta, as maiores doses de vinhaça proporcionaram os menores acúmulos de matéria seca, sendo $100 \mathrm{~m}^{3} \mathrm{ha}^{-1}$ a melhor dose observada. Para a cultura do milho, a dose de $100 \mathrm{~m}^{3} \mathrm{ha} \mathrm{H}^{-1}$ de vinhaça proporcionou produtividade de silagem semelhante à adubação mineral e foi capaz de suprir a necessidade de potássio também para o cultivo do milho safrinha. Em relação aos atributos químicos do solo, não se observaram alterações significativas na camada avaliada (0$10 \mathrm{~cm}$ ). A utilização da vinhaça como fonte de potássio mostrou-se uma alternativa tecnicamente viável e a sua utilização em nível de lavoura uma forma de descarte desse resíduo.

Palavras-chave: doses, produtividade de grãos, produção de forragem.

\section{ABSTRACT}

Vinasse is a residue from the distillation process of alcohol and it is rich in potassium $(K)$. Its application in soil can increase the availability of the nutrient as well as cause changes in the chemical properties of soil. The objective of this study was to evaluate the technical viability of using vinasse as an alternative source of potassium in black oat/corn silage/short-season corn succession, and possible changes in soil chemical properties in the $0-10 \mathrm{~cm}$ layer. The experiment was conducted in the city of Ajuricaba (RS) in the period of April 2010 to August 2011. The treatments used were: T1) NPK fertilizers; T2) $N+P$ without vinasse; T3) $\mathrm{N}+P+50 \mathrm{~m}^{3} \mathrm{ha}^{-1}$ of vinasse; T4) $\mathrm{N}+P+100 \mathrm{~m}^{3} \mathrm{ha}^{-1}$ of vinasse; T5) $N+P+150 \mathrm{~m}^{3} \mathrm{ha}^{-1}$ of vinasse and T6) $N+P+200 \mathrm{~m}^{3} \mathrm{ha}^{-1}$ of vinasse. In black oat, total foliar content of $P, K$ and dry matter accumulation were evaluated. In corn silage, plant height, ear insertion height and forage productivity were assessed. While in short-season corn, the weight of a thousand seeds and the grain yield were measured. Regarding soil chemical properties, $\mathrm{pH}, \mathrm{P}, \mathrm{K}, \mathrm{Ca}, \mathrm{Mg}$ content and cation exchange capacity were evaluated. In black oat, the highest doses of vinasse presented the lowest accumulations of dry matter and the best dose observed being that of $100 \mathrm{~m}^{3} \mathrm{ha}^{-1}$. For corn crop, the quantity of $100 \mathrm{~m}^{3} \mathrm{ha}^{-1}$ of vinasse provided similar silage productivity to mineral fertilizer, and was also able to meet the needs of potassium for the cultivation of short-season corn. In relation to soil chemical properties, significant changes in the $0-10 \mathrm{~cm}$ layer were not observed. The use of vinasse as a source of potassium showed to be a technically viable alternative and a way to dispose of this waste in a crop level.

Key words: dose, grain yield, forage production.

\section{INTRODUÇÃO}

O Rio Grande do Sul (RS) não se caracteriza como um grande produtor de canade-açúcar, todavia essa gramínea é cultivada na maioria das pequenas propriedades rurais, para a

${ }^{\text {I} C e n t r o ~ d e ~ E d u c a c ̧ a ̃ o ~ S u p e r i o r ~ N o r t e ~(C E S N O R S), ~ U n i v e r s i d a d e ~ F e d e r a l ~ d e ~ S a n t a ~ M a r i a ~(U F S M), ~ 98400-000, ~ F r e d e r i c o ~ W e s t p h a l e n, ~ R S, ~}$ Brasil.E-mail: claudirbasso@gmail.com.*Autor para correspondência.

"Programa de Pós-graduação em Agronomia Agricultura e Ambiente, UFSM, Frederico Westphalen, RS, Brasil. 
alimentação animal e também como matéria-prima na produção de melado e principalmente aguardente, em agroindústrias familiares na região Noroeste do Estado. Para a produção de álcool ou aguardente, gera-se um resíduo, a vinhaça, que é rica em potássio (K) (BARROS et al., 2010), além de outros nutrientes, como o cálcio $(\mathrm{Ca})$ e magnésio $(\mathrm{Mg})$. Esses autores, após 10 anos de aplicação da vinhaça em um solo cultivado com cana-de-açúcar, observaram alterações nas propriedades químicas do solo com incremento dos teores de matéria orgânica e macronutrientes e diminuição dos teores de micronutrientes.

O K é um dos nutrientes mais abundantes no tecido vegetal de praticamente todas as espécies vegetais e, por apresentar-se predominantemente na forma iônica $\mathrm{K}^{+}$, seu retorno ao solo é muito rápido, ocorrendo logo após a senescência das plantas (PAVINATO et al., 2008). Com relação à cultura do milho, quando o objetivo é a produção de grãos, a maior parte do $\mathrm{K}$ absorvido retorna ao solo após a colheita. Porém, de acordo com YAMADA \& ROBRTS (2005), no milho destinado à produção de silagem, deve-se tomar cuidado na recomendação do nutriente pelo corte e retirada de todo material. Estudando a dinâmica de nutrientes no solo em áreas para produção de milho silagem, UENO et al. (2011) observaram uma exportação média de $76 \mathrm{~kg} \mathrm{ha}^{-1}$ a mais de $\mathrm{K}$, quando comparada ao milho para produção de grãos. Logo, a utilização da vinhaça como fonte de $\mathrm{K}$, além de representar uma importante alternativa de descarte, pode reduzir a dependência de insumos externos e, consequentemente, redução do custo de produção.

Mesmo se desenvolvendo em meses cuja soma térmica diária é baixa e que pode comprometer o potencial produtivo, a semeadura do milho safrinha é muito utilizada buscando boa produção de palhada, contribuindo para a sustentabilidade do sistema. Assim, a sequência aveia-preta/milho silagem/ milho safrinha é utilizada na grande maioria das propriedades da Região Noroeste do Rio Grande do Sul (RS). No entanto, são raros os casos em que se utiliza a vinhaça como fonte de K. Por isso, o trabalho objetivou avaliar a viabilidade técnica da utilização da vinhaça como fonte alternativa de $\mathrm{K}$ na sucessão aveia preta/milho silagem/milho safrinha, além de possíveis alterações em atributos químicos do solo na camada de $0-10 \mathrm{~cm}$.

\section{MATERIAL E MÉTODOS}

O experimento foi conduzido no Município de Ajuricaba (RS), no período 04/2010 a 06/2011 num solo classificado como Latossolo Vermelho
Eutrófico típico (EMBRAPA, 2006) e com relevo plano. Antecedendo a instalação do experimento, realizou-se amostragem do solo na camada de $0-10 \mathrm{~cm}$ de profundidade para caracterização química e física, sendo observados os seguintes atributos: argila $600 \mathrm{~g}$ $\mathrm{kg}^{-1}$, matéria orgânica $16,5 \mathrm{~g} \mathrm{~kg}^{-1}, \mathrm{pH}$ em $\mathrm{H}_{2} \mathrm{O}(1: 1)$ 5,4 , Índice SMP 5,8, P disponível 5,9mg dm $\mathrm{m}^{-3}, \mathrm{~K}$ trocável $189 \mathrm{mg} \mathrm{dm}^{-3}$ (extrator Mehlich 1); Ca trocável $6,4 \mathrm{cmol}_{\mathrm{c}} \mathrm{dm}^{-3}, \mathrm{Mg}$ trocável 3,2 $\mathrm{cmol}_{\mathrm{c}} \mathrm{dm}^{-3}, \mathrm{Al}$ trocável $0,1 \mathrm{cmol}_{\mathrm{c}} \mathrm{dm}^{-3}$ (extrator $\mathrm{KCl} 1 \mathrm{~mol} \mathrm{~L}^{-1}$ ), $\mathrm{H}+\mathrm{Al} 5,5 \mathrm{cmol}_{\mathrm{c}}$ $\mathrm{dm}^{-3}$, CTC $15,5 \mathrm{cmol}_{\mathrm{c}} \mathrm{dm}^{-3}$ e saturação por bases de $64,7 \%$. A área, por mais de 15 anos, foi cultivada sob sistema plantio direto com a sucessão trigo/soja. No último ano agrícola e antecedendo a instalação do experimento, a área foi cultivada com aveia-preta (Avena strigosa Schreb) no inverno e capim-sudão (Shorghum sudanense L.) no verão.

$\mathrm{O}$ delineamento experimental foi $\mathrm{o}$ de blocos completamente casualizados com seis tratamentos e quatro repetições, com as parcelas medindo 4,0x3,0m. Os tratamentos avaliados foram: T1) adubação mineral (NPK); T2) N+P sem vinhaça; T3) $\mathrm{N}+\mathrm{P}+50 \mathrm{~m}^{3} \mathrm{ha}^{-1}$ de vinhaça; T4) $\mathrm{N}+\mathrm{P}+100 \mathrm{~m}^{3}$ ha $^{-1}$ de vinhaça; T5) $\mathrm{N}+\mathrm{P}+150 \mathrm{~m}^{3} \mathrm{ha}^{-1}$ de vinhaça; e T6) $\mathrm{N}+\mathrm{P}+200 \mathrm{~m}^{3} \mathrm{ha}^{-1}$ de vinhaça. A vinhaça utilizada foi obtida de uma micro-destilaria para produção de aguardente e apresentava um $\mathrm{pH}$ de 4,37 e um teor 3.320, 728 e $35 \mathrm{mg} \mathrm{L}^{-1}$ de $\mathrm{K}$, Ca e $\mathrm{Mg}$, respectivamente. A aplicação de vinhaça com a utilização de regadores foi realizada após o estabelecimento da aveia preta e parcelada em dois momentos, sendo o primeiro no início do desenvolvimento vegetativo com metade da dose e o segundo com o restante da dose na fase de emborrachamento, não sendo mais reaplicada nos dois outros cultivos com milho silagem e do milho safrinha. Para todos os tratamentos, a adubação química seguiu a recomendação da CQFS-RS/SC (2004).

A semeadura da aveia-preta foi a lanço $\left(80 \mathrm{~kg} \mathrm{ha}^{-1}\right)$ no dia 10/05/11, seguida de leve gradagem. Vinte e cinco dias após a semeadura da aveia preta, efetuou-se a primeira aplicação da vinhaça e a adubação química no T1 (adubação mineral NPK), com aplicação de $150 \mathrm{~kg} \mathrm{ha}^{-1}$ da fórmula comercial 10-16-12. Para os demais tratamentos em que a fonte de $\mathrm{K}$ foi a vinhaça, a exigência de $\mathrm{N}$ e $\mathrm{P}$ foi suprida com a aplicação a lanço de uréia e superfosfato triplo, respectivamente.

No pleno florescimento da aveia, foi realizada aleatoriamente, em 50 plantas de cada parcela, a coleta da folha bandeira para determinação dos teores totais de $\mathrm{P}$ e $\mathrm{K}$ no tecido vegetal (TEDESCO et al., 1995). Posteriormente, no estádio de grão leitoso, foi efetuada amostragem em uma 
área útil de $0,25 \mathrm{~m}^{2}$ para avaliação do acúmulo de matéria seca da aveia preta. No dia 06/09/2010, foi realizada dessecação da aveia com utilização de $960 \mathrm{~g}$ i.a glyphosate ha-1.

A semeadura do milho (Attak) foi realizada em 18/10/2010 com semeadora tratorizada, num espaçamento entre linhas de $76 \mathrm{~cm}$, a uma densidade de 60.000 sementes ha $^{-1}$ e uma população final de plantas estimada em 57.500 plantas ha $^{-1}$. Como adubação de base na cultura do milho, utilizou-se diamônio fosfato (DAP) para todos os tratamentos com adubação mineral e para o T1 (adubação mineral NPK), cloreto de potássio foi a fonte utilizada como fonte de K. A adubação de cobertura no milho (uréia) foi realizada quando as plantas se encontravam com quatro a cinco folhas desenvolvidas.

No florescimento do milho silagem, foi coletada, em 40 plantas por parcela, a folha oposta e abaixo da espiga, excluindo-se as extremidades e, em seguida, secando-se em estufa a $65^{\circ} \mathrm{C}$ para posterior análise do tecido vegetal (TEDESCO et al., 1995). Além disso, dias antes do processo de ensilagem, foram avaliadas a altura de planta (superfície do solo até a última folha) e a altura de inserção da espiga (superfície do solo até altura de inserção da base da espiga), medindo-se cinco plantas da área útil de cada parcela. Para a determinação da produtividade de forragem, foram cortadas $10 \mathrm{~cm}$ acima da superfície do solo as plantas das duas linhas centrais de cada parcela, numa extensão de dois metros $\left(3,0 \mathrm{~m}^{2}\right)$ de área útil, quando a linha do leite atingiu 50\% do grão. As plantas foram trituradas em triturador forrageiro estacionário e a massa obtida foi transformada em $\mathrm{kg} \mathrm{ha}^{-1}$.

Após a colheita do milho silagem, a área experimental foi dessecada com $760 \mathrm{~g}$ i.a glyphosate $\mathrm{ha}^{-1}$ para posterior semeadura do milho safrinha, realizada em 23/01/2011. Utilizou-se o híbrido duplo AS 1590 YG, com população final de plantas estimada em 57.000 plantas $\mathrm{ha}^{-1}$, seguindo-se o mesmo procedimento descrito para o milho silagem. No milho safrinha, foram colhidas as espigas das duas linhas centrais de cada parcela, numa extensão de dois metros $\left(3,0 \mathrm{~m}^{2}\right)$ para avaliação da produtividade $(\mathrm{kg}$ $\mathrm{ha}^{-1}$ ), sendo o teor de umidade corrigido para $13 \%$.

Quanto aos atributos químicos do solo, dez meses após a segunda aplicação de parte da vinhaça ocorrida no emborrachamento da aveia preta, foi realizada amostragem de solo na profundidade de $0-10 \mathrm{~cm}$ nos tratamentos que receberam as doses de 0,100 e $200 \mathrm{~m}^{3} \mathrm{ha}^{-1}$ de vinhaça, buscando-se verificar possíveis alterações no $\mathrm{pH}, \mathrm{CTC}(\mathrm{pH} 7,0)$, e nos teores de matéria orgânica, $\mathrm{P}$ disponível; $\mathrm{K}, \mathrm{Ca}$; e Mg trocáveis (TEDESCO et al., 1995).
Os resultados obtidos foram submetidos à análise de variância e, quando significativa para as variáveis analisadas, as médias foram comparadas pelo teste de Dunnett a 5,0\%. Para as doses de vinhaça, procedeu-se com análise de regressão, ajustando-se ao grau significativo da equação. Para essas análises, utilizou-se o programa estatístico SAS, versão 8.2 for Windows (2000).

\section{RESULTADOS E DISCUSSÃO}

Durante todo desenvolvimento das culturas da sucessão aveia preta/milho silagem/milho safrinha que fizeram parte desse estudo, não houve, em nenhum momento, deficiência hídrica que possa ter comprometido o desenvolvimento das culturas. Fazendo-se um resumo da análise da variância e para as variáveis analisadas, só houve diferença significativa para a altura de planta do milho silagem e para as produtividades de matéria seca da parte aérea da aveia preta, milho silagem (forragem) e produtividade de grãos do milho safrinha. Não houve diferença significativa para os teores totais foliares de $\mathrm{P}$ e K para a cultura da aveia preta e para o milho silagem, bem como para o peso de mil sementes do milho safrinha.

Quanto à matéria seca da aveia preta, a tabela 1 mostra uma maior produtividade $\left(4,01 \mathrm{Mg} \mathrm{ha}^{-1}\right)$ com a utilização de $100 \mathrm{~m}^{3}$ ha $^{-1}$ de vinhaça. Quando se compara essa produtividade com a obtida com aplicação de N+P e sem K, o incremento foi de 16,2\% com a utilização da vinhaça, ou seja, um aumento de $5,6 \mathrm{~kg}$ de matéria seca por $\mathrm{m}^{3}$ de vinhaça aplicada. Para as doses acima de $100 \mathrm{~m}^{3}$ ha ${ }^{-1}$ de vinhaça, houve uma redução na produtividade de matéria seca da aveia preta, o que pode estar relacionado ao momento da primeira aplicação da vinhaça realizada no estádio inicial de desenvolvimento da aveia preta. Avaliando o efeito de diferentes doses de vinhaça na germinação e vigor de sementes de milho, PEREIRA et al. (1992) observaram que doses de vinhaça acima de $400 \mathrm{~m}^{3}$ $\mathrm{ha}^{-1}$, mesmo aplicadas 30 dias antes da semeadura, provocaram redução no vigor das plantas. $\mathrm{O}$ efeito negativo da utilização de vinhaça sobre a germinação e o desenvolvimento inicial de algumas espécies também foi constatado por RAMOS et al. (2008), os quais verificaram que a aplicação de $150 \mathrm{~m}^{3} \mathrm{ha}^{-1} \mathrm{de}$ vinhaça prejudicou a emergência e o desenvolvimento inicial de plantas de amendoim e girassol. O efeito negativo da utilização de doses maiores de $100 \mathrm{~m}^{3}$ ha $^{-1}$ de vinhaça sobre a produtividade de matéria seca da aveia preta no presente trabalho fica evidente no comparativo com a produtividade obtida com adubação mineral, em que a aplicação de 150 e 
Tabela 1 - Teste de médias para a produtividade de matéria seca da parte aérea da aveia preta, altura de plantas e produtividade de forragem do milho silagem e produtividade de grãos do milho safrinha, em função da adição de potássio via adubação mineral e vinhaça. UFSM, Campus de Frederico Westphalen (RS), 2010/11.

\begin{tabular}{|c|c|c|c|c|}
\hline \multirow{2}{*}{ Tratamentos } & \multirow{2}{*}{$\begin{array}{c}\text { Aveia preta } \\
\mathrm{Mg} \mathrm{ha}^{-1}\end{array}$} & \multicolumn{2}{|c|}{-------------------Milho silagem---------------------- } & \multirow{2}{*}{$\begin{array}{c}\text { Milho safrinha } \\
\qquad \mathrm{Mg} \mathrm{ha}^{-1}\end{array}$} \\
\hline & & Alt. planta - m & Forragem - Mg ha ${ }^{-1}$ & \\
\hline Adubação mineral $^{(1)}$ & 3,70 & 1,20 & 54,10 & $4,60^{+}$ \\
\hline $\mathrm{N}+\mathrm{P}+0 \mathrm{~m}^{3} \mathrm{ha}^{-1(2)}$ & 3,45 & 1,19 & 51,55 & $3,65^{-}$ \\
\hline $\mathrm{N}+\mathrm{P}+50 \mathrm{~m}^{3} h \mathrm{a}^{-1}$ & 3,70 & 1,20 & 54,12 & $4,93^{+}$ \\
\hline $\mathrm{N}+\mathrm{P}+100 \mathrm{~m}^{3} \mathrm{ha}^{-1}$ & $4,01^{+}$ & 1,22 & $55,57^{+}$ & $5,15^{++}$ \\
\hline $\mathrm{N}+\mathrm{P}+150 \mathrm{~m}^{3} \mathrm{ha}^{-1}$ & 3,30 & 1,22 & $55,50^{+}$ & $4,60^{+}$ \\
\hline $\mathrm{N}+\mathrm{P}+200 \mathrm{~m}^{3} h \mathrm{a}^{-1}$ & 3,39 & $1,24^{+}$ & $58,65^{++}$ & $4,46^{+}$ \\
\hline Coeficiente variação - \% & 6,94 & 2,28 & 2,90 & 4,09 \\
\hline
\end{tabular}

${ }^{1}$ Adubação mineral (NPK); ${ }^{(2)} \mathrm{N}+\mathrm{P}$ mineral sem K; ${ }^{++}$Significativo e superior à adubação mineral (NPK) pelo teste de Dunnett a 5\%; ${ }^{+}$Significativo e superior a N + P mineral sem K pelo teste de Dunnett a 5\%; "- Significativo e inferior à adubação mineral (NPK) pelo teste de Dunnett a $5 \%$.

$200 \mathrm{~m}^{3}$ ha $^{-1}$ de vinhaça reduziu em 10,8 e $8,4 \%$ a produtividade de matéria seca no comparativo a adubação mineral.

A altura de planta é um parâmetro importante na produção de silagem. Quando se observa a tabela $1 \mathrm{e}$ para as diferentes doses de vinhaça, a maior altura de planta no milho silagem foi de $1,24 \mathrm{~m}$, observada na aplicação de $200 \mathrm{~m}^{3} \mathrm{ha}^{-1}$ de vinhaça, sendo significativamente superior ao tratamento sem adição de $\mathrm{K}$.

Quanto à produtividade de forragem, houve diferença significativa quando se compara o fornecimento de $\mathrm{K}$ via adubação mineral com algumas doses de vinhaça (Tabela 1). Nesse comparativo, as doses de 100,150 e $200 \mathrm{~m}^{3} \mathrm{ha}^{-1}$ de vinhaça foram estatisticamente superiores à adubação mineral, sendo, na dose de $200 \mathrm{~m}^{3} \mathrm{ha}^{-1}$, observada à maior produtividade de forragem $\left(58,65 \mathrm{Mg} \mathrm{ha}^{-1}\right)$. A menor produtividade de forragem $\left(51,55 \mathrm{Mg} \mathrm{ha}^{-1}\right)$ foi observada no tratamento sem suplementação de $\mathrm{K}\left(\mathrm{N}+\mathrm{P}+0 \mathrm{~m}^{3} \mathrm{ha}^{-1}\right.$ de vinhaça). Quando se comparam os tratamentos com aplicação de 50,100,150,200m $\mathrm{ha}^{-1}$ de vinhaça e o tratamento com adubação de $\mathrm{N}+\mathrm{P}$ sem vinhaça, o incremento na produção de silagem foi de $5,0,7,8,7,6,13,7 \%$, respectivamente, mostrando uma resposta linear na produtividade de forragem do milho silagem com o aumento da dose de vinhaça, conforme mostra a equação da figura $1 \mathrm{a}$. Trabalhando em casa de vegetação, com o mesmo tipo de solo e doses crescentes de vinhaça, 0, 100, 200, 400, 600, 800 e $1.000 \mathrm{~m}^{3} \mathrm{ha}^{-1}$, PEREIRA et al. (1992) também observaram incremento na matéria seca da parte área do milho como o incremento da dose de vinhaça até $400 \mathrm{~m}^{3} \mathrm{ha}^{-1}$.
Mesmo o teor de $\mathrm{K}$ no solo sendo considerado alto, segundo CQFS-RS/SC (2004), houve resposta à adubação potássica no cultivo do milho silagem. Por isso que YAMADA \& ROBERTS (2005) afirmam da necessidade de revisão na calibração da recomendação de adubação potássica na cultura do milho, mesmo quando o solo apresenta teor alto desse nutriente. Essa preocupação para o esgotamento de $\mathrm{K}$ no solo em áreas com cultivo de gramíneas para produção de silagem também é apontada por KAMINSKI et al. (2007).

Comparando $\mathrm{o}$ fornecimento $\mathrm{K}$ via adubação mineral com o tratamento em que somente foi aplicado $\mathrm{N}$ e $\mathrm{P}$ sem vinhaça, a adição de $\mathrm{K}$ incrementou em $26 \%$ a produtividade de grãos do milho safrinha. Isso reforça a preocupação de alguns autores, conforme colocado anteriormente com relação ao esgotamento de $\mathrm{K}$ no solo em áreas para produção de forragem, já que os teores no solo eram considerados altos na instalação do experimento. Quando se compara a produtividade de grãos de milho safrinha para as diferentes doses de vinhaça, a maior produtividade $\left(5,15 \mathrm{Mg} \mathrm{ha}^{-1}\right)$ foi observada na aplicação de $100 \mathrm{~m}^{3} \mathrm{ha}^{-1}$ de vinhaça. No comparativo entre as doses de 50 e $100 \mathrm{~m}^{3} \mathrm{ha}^{-1}$ de vinhaça, com o tratamento sem adição de $\mathrm{K}$, essa foi de 1.280 e $1.500 \mathrm{~kg} \mathrm{ha}^{-1}$, respectivamente, representando um incremento de 35 e $41 \%$ na produtividade de grãos do milho safrinha. Semelhante ao observado para a produtividade de matéria seca da aveia preta, doses de vinhaça acima de $100 \mathrm{~m}^{3} \mathrm{ha}^{-1}$ reduziram a produtividade de grãos do milho safrinha, sendo essa redução de 10,6 e 13,4\% para as dose de 150 e $20 \mathrm{~m}^{3}$ ha ${ }^{-1}$ de vinhaça, respectivamente, o que fica evidente quando se observa a equação da 


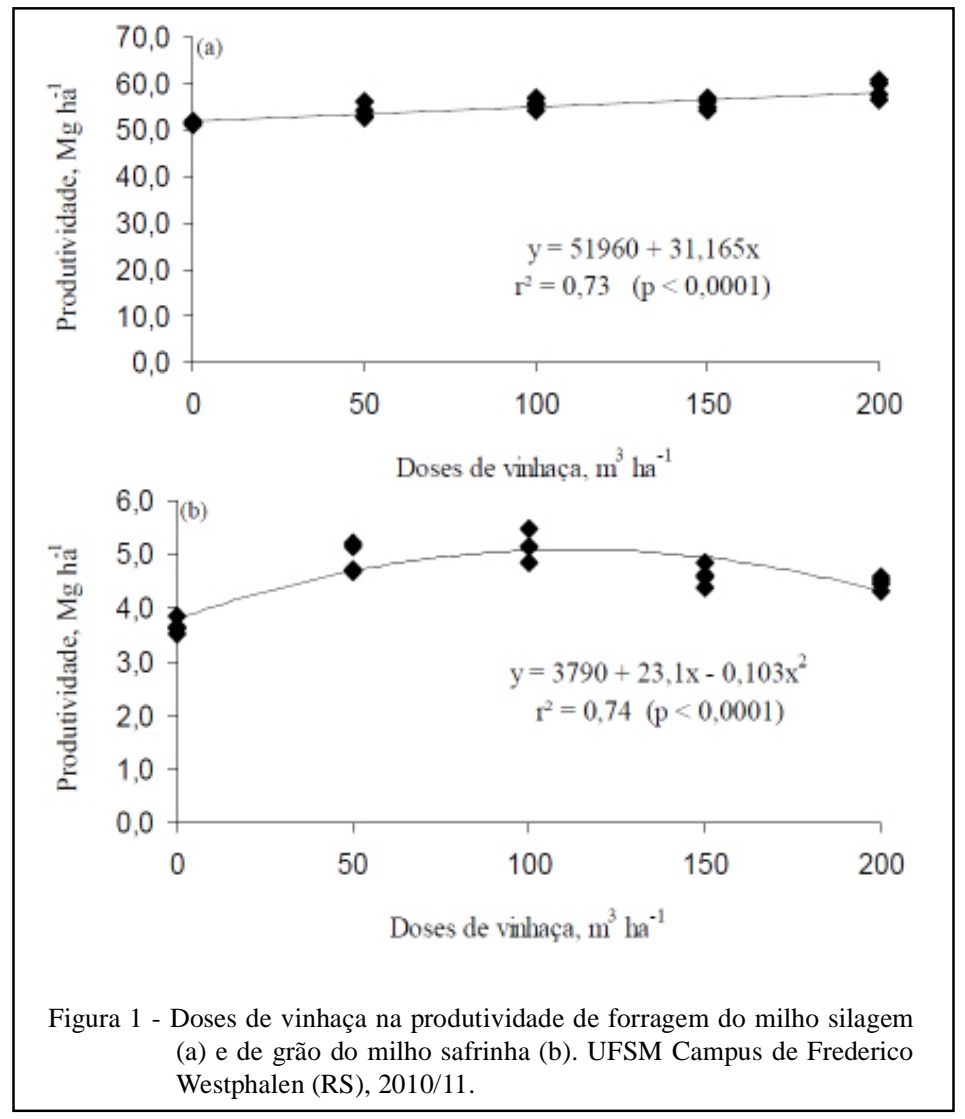

figura 1 b. Quando da aplicação de altas doses de vinhaça, TEJADA \& GONZALES (2005) também observaram redução na produtividade e qualidade de grãos de trigo, bem como na estrutura e densidade do solo. Para esses autores, a alta concentração de sódio e ácidos fúlvicos da vinhaça transportados para o interior do solo interferiu negativamente na condutividade elétrica, na absorção de nutrientes pelas plantas e na estrutura deste.

Com relação aos atributos químicos do solo e quanto ao $\mathrm{pH}$, não foram observadas diferenças significativas para as diferentes doses de vinhaça aplicadas, quando comparadas à análise feita por ocasião da instalação do experimento (Tabela 2). Avaliando a aplicação anual de $150 \mathrm{~m}^{3} \mathrm{ha}^{-1}$ de vinhaça, BARROS et al. (2010) também não observaram mudanças no pH do solo, contudo, os autores alertam que, nos primeiros 10 dias após aplicação da vinhaça, o pH do solo pode sofrer uma redução significativa e posteriormente elevar-se abruptamente, podendo atingir valores superiores a 7 .

Esperava-se que a utilização da vinhaça elevasse o teor de nutrientes no solo, principalmente $\mathrm{K}$, pois, observando a dosagem e o teor na vinhaça, nota-se que o aporte desse nutriente foi na ordem de 166,332 e $664 \mathrm{~kg} \mathrm{ha}^{-1}$ para as doses de 50, 100 e $200 \mathrm{~m}^{3} \mathrm{ha}^{-1}$, respectivamente, o que não ocorreu. Mesmo não havendo diferença significativa entre os tratamentos, a aplicação de 100 e $200 \mathrm{~m}^{3} \mathrm{ha}^{-1}$ de vinhaça incrementou em 3,1 e $6,9 \%$ o teor de $\mathrm{K}$ no solo, comparado aos teores antes da instalação do experimento. Comparando áreas de 1 a 20 anos com aplicação anual de $150 \mathrm{~m}^{3} \mathrm{ha}^{-1}$ de vinhaça a uma área sem aplicação de vinhaça, PAULINO et al. (2011) observaram maior teor de $\mathrm{K}$ nas área com aplicação de K, mesma observação feita por outros autores (BEBÉ et al., 2009; BARROS et al., 2010).

A elevada precipitação pluviométrica, observada no período entre a aplicação da vinhaça e a realização da análise de solo, pode ter favorecido a lixiviação do $\mathrm{K}$ para camadas abaixo de $10 \mathrm{~cm}$, além da maior extração em função das maiores produtividades de silagem e grãos do milho safrinha. Por isso, SILVA et al. (2007) alertam com relação à quantidade de vinhaça aplicada ao solo como fertilizante, para que não exceda a capacidade de retenção de água pelo solo, que pode potencializar a perda de $\mathrm{K}$ por lixiviação. Também não Foram 
Tabela 2 - Atributos químicos do solo na profundidade de $0-10 \mathrm{~cm}$ avaliados dez meses após a aplicação da vinhaça. UFSM, Frederico Westphalen (RS), 2010/11.

\begin{tabular}{|c|c|c|c|c|c|c|}
\hline Tratamentos & $\begin{array}{c}\mathrm{pH} \\
\left(\mathrm{H}_{2} \mathrm{O}\right)^{(1)}\end{array}$ & $\begin{array}{c}\text { Fósforo } \\
\text { Disponível }\end{array}$ & 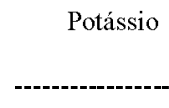 & Cálcio & 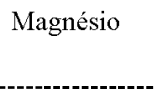 & $\begin{array}{c}\text { CTC } \\
\mathrm{pH}(7,0)\end{array}$ \\
\hline & \multicolumn{6}{|c|}{ - } \\
\hline Análise inicial ${ }^{(2)}$ & $5,4 \mathbf{a}$ & $5,9 \mathrm{a}$ & $189 \mathrm{~A}$ & $6,4 \mathrm{~B}$ & $3,2 \mathrm{a}$ & $15,3 \mathrm{~b}$ \\
\hline $\mathrm{N}+\mathrm{P}+0 \mathrm{~m}^{3} h \mathrm{a}^{-1(2)}$ & $5,2 \mathrm{a}$ & $7,2 \mathrm{a}$ & $182 \mathrm{~A}$ & $10,7 \mathrm{~A}$ & $3,6 \mathrm{a}$ & $20,4 \mathrm{a}$ \\
\hline $\mathrm{N}+\mathrm{P}+100 \mathrm{~m}^{3} \mathrm{ha}^{-1}$ & $5,5 \mathrm{a}$ & 10,9 a & $195 \mathrm{~A}$ & $11,1 \mathrm{a}$ & $3,7 \mathrm{a}$ & $19,7 \mathrm{a}$ \\
\hline $\mathrm{N}+\mathrm{P}+200 \mathrm{~m}^{3} \mathrm{ha}^{-1}$ & $5,5 \mathrm{a}$ & $10,9 \mathbf{a}$ & $202 \mathrm{a}$ & $12,2 \mathbf{a}$ & $3,8 \mathrm{a}$ & $20,0 \mathrm{a}$ \\
\hline $\mathrm{Cv}-\%$ & 12,5 & 18,7 & 13,2 & 8,38 & 7,43 & 18,6 \\
\hline
\end{tabular}

${ }^{(1)}$ Médias seguidas da mesma letra não diferem estatisticamente pelo teste de Tukey $(\mathrm{P}>0,05) .{ }^{(2)}$ Refere-se à análise química do solo feita por ocasião da instalação do experimento.

encontradas diferenças para os teores de $\mathrm{K}$ trocável do solo, quando 50 e $100 \%$ da recomendação do K para a cultura do milho foram supridas com vinhaça (BEBÉ et al., 2008).

\section{CONCLUSÃO}

A utilização da vinhaça como fonte de $\mathrm{K}$ na sucessão aveia preta/milho silagem/milho safrinha pode substituir a adubação mineral com cloreto de $\mathrm{K}$ e com residual para os cultivos subsequentes. Mesmo com a utilização de doses de $200 \mathrm{~m}^{3} \mathrm{ha}^{-1}$ de vinhaça, não houve alteração nos atributos químicos do solo dez meses após a aplicação da vinhaça, o que pode ser atribuído ao curto tempo de experimentação. Supõe-se que, em longo prazo, adições continuadas de vinhaça possam provocar alterações significativas em alguns atributos químicos do solo.

\section{REFERÊNCIAS}

BARROS, R.P. et al. Alterações em atributos químicos de solo cultivado com cana-de-açúcar e adição de vinhaça. Pesquisa Agropecuária Tropical, v.40, n.3, p.341-346, 2010. Disponível em: <http://www.revistas.ufg.br/index.php/pat/article/view/6422/7896>. Acesso em: 18 maio, 2011. doi: 10.5216/pat.v40i3.5841

BEBÉ, F.V. et al. Desenvolvimento do milho e alterações químicas em solo sob aplicação de vinhaça. Revista de Biologia e Ciência da Terra, v.8, n.2, p.191-196, 2008. Disponível em: <http://eduep. uepb.edu.br/rbct/sumarios/pdf/21desenvolvimento.pdf >. Acesso em: 21 abr. 2011. doi: 10.1590/S0100-69162012000400013.

BEBÉ, F.V. et al. Avaliação de solos sob diferentes períodos de aplicação com vinhaça. Revista Brasileira de Engenharia Agrícola e Ambiental, v.13, p.781-787, 2009. Disponível em: <http://www.scielo.br/scielo.php?pid=S141543662011000100004\&script=sci_arttext $>$. Acesso em: 12 fev. 2011. doi: $10.1590 /$ S1415-43662011000100004.
COMISSÃO DE QUÍMICA E FERTILIDADE DO SOLO (CQFS RS/SC). Manual de adubação e calagem para os estados do Rio Grande do Sul e Santa Catarina. 10.ed. Porto Alegre: Sociedade Brasileira de Ciência do Solo/Núcleo Regional Sul, 2004. 400p.

EMPRESA BRASILEIRA DE PESQUISA AGROPECUÁRIA (EMBRAPA). Tecnologias de produção de soja - região central do Brasil - 2007. Londrina: Embrapa Soja, Embrapa Cerrados, Embrapa Agropecuária Oeste, 2006. 225p. (Sistemas de Produção).

KAMINSKI, J. et al. Depleção de formas de potássio do solo afetada por cultivos sucessivos. Revista Brasileira de Ciência do Solo, v.31, p.1003-1010, 2007. Disponível em: <http://www.scielo. $\mathrm{br} / \mathrm{scielo}$.php? $\mathrm{pid}=\mathrm{S} 0100-06832007000500017 \&$ script $=\mathrm{sci}_{-}$ arttext>. Acesso em: 17 set. 2012. doi: 10.1590/S010006832007000500017.

PAULINO, J. et al. Estudo exploratório do uso da vinhaça em longo do temo.II. Características da cana-de-açúcar. Revista Brasileira de Engenharia Agrícola e Ambiental, v.15, n.3, p.244-249, 2011. Disponível em: <http://www.scielo.br/scielo.php?pid=S1415$43662011000300004 \&$ script $=$ sci_arttext $>$. Acesso em: 13 set. 2012. doi: $10.1590 / \mathrm{S} 1415-43662011000300004$.

PAVINATO, P.S. et al. Nitrogênio e potássio em milho irrigado: análise técnica e econômica da fertilização. Ciência Rural, v.38, n.2, p.358-364, 2008. Disponível em: <http://dx.doi. org/10.1590/S0103-84782008000200010.doi:10.1590/S010384782008000200010>. Acesso em: 14 maio, 2011. doi: 10.1590/ S0103-84782008000200010.

PEREIRA, J.P. et al. Efeito da adição de diferentes dosagens de vinhaça a um Latossolo Vermelho-Amarelo distrófico na germinação e vigor de sementes de milho. Revista Brasileira de Sementes, v.14, n.2, p.147-150, 1992. Disponível em: <http:// www.abrates.org.br/revista/artigos/1992/v14n2/artigo09.pdf > . Acesso em: 14 mar. 2011.

RAMOS, N.P. et al. Efeito da vinhaça no desenvolvimento inicial de girassol, mamona e amendoim em casa de vegetação. Bragantia, v.67, n.3, p.685-692, 2008. Disponível em: <http:// www.scielo.br/pdf/brag/v67n3/a17v67n3.pdf $>$. Acesso em: 24 maio, 2011. doi: 10.1590/S0006-87052008000300017. 
SILVA, M.A.S. et al. Uso de vinhaça e impactos nas propriedades do solo e lençol freático. Revista Brasileira de Engenharia Agrícola e Ambiental, v.11, p.108-114, 2007. Disponível em: <http://www.scielo.br/pdf/rbeaa/v11n1/v11n1a14.pdf>. Acesso em: 23 mar. 2011. doi: 10.1590/S1415-43662007000100014.

TEDESCO, M.J. et al. Análise de solo, plantas e outros materiais. Porto Alegre, Universidade Federal do Rio Grande do Sul, 1995. 174p.

TEJADA, M.; GONZALEZ, J.L. Beet vinasse applied to wheat under dryland conditions affects soil properties and yield. European Journal of Agronomy, v.23, p.336-347, 2005.
Disponível em: <http://www.sciencedirect.com/science/article/pii/ S1161030105000237>. Acesso em: 09 set. 2012. doi: 10.1016/j. eja.2005.02.005.

UENO, R.K. et al. Dinâmica dos nutrientes do solo em áreas destinadas à produção de milho para forragem. Revista Brasileira de Tecnologia Aplicada nas Ciências Agrárias, v.4, n.1, p.182203, 2011. Disponível em: <http://revistas.unicentro.br/index.php/ repaa/article/view/1427/1485>. Acesso em: 09 set. 2012.

YAMADA, T.; ROBERTS, T.L. Potássio na agricultura brasileira. Piracicaba: Associação Brasileira para Pesquisa da Potassa e do Fosfato, 2005. 841p. 